\title{
Optimisation of a photocatalytic water treatment using Response Surface Methodology and Quality by Design approach
}

\author{
El Mountassir El Mouchtari ${ }^{* a, b}$, Magalie Claeys-Bruno ${ }^{c}$, Salah Rafqah $^{\mathrm{a}}$, \\ Diane Manzon ${ }^{\mathrm{c}}$, Hafid Anane ${ }^{\mathrm{a}}$, Stéphanie Lebarillier ${ }^{\mathrm{b}}$, Anne Piram ${ }^{*}$, Samir \\ Briche $^{\mathrm{d}}$, Pascal Wong-Wah-Chung ${ }^{\mathrm{b}}$
}

a Université Cadi Ayyad, LCAM, Faculté Polydisciplinaire de Safi, Maroc.

b Aix Marseille Univ, CNRS, LCE, Marseille, France

c Aix Marseille Univ, Univ Avignon, CNRS, IRD, IMBE, Marseille, France.

d Département stockage de l'énergie et revêtements multifonctionnels, MAScIR, Rabat, Morocco

corresponding authors:

Anne Piram: Aix-Marseille Université - LCE - Europole de l'Arbois - bat. Villemin BP80 - anne.piram@univ-amu.fr

El Mountassir El Mouchtari: Laboratoire de Chimie Analytique et Moléculaire (LCAM) - Département de Chimie - Faculté polydisciplinaire de Safi - Université Cadi Ayyad Morocco / Aix-Marseille Université - Europole de l'Arbois -bat. Villemin - BP80 13545 Aix-en-Provence- France - el-mountassir.el-mouchtari@etu.univ-amu.fr 


\title{
Optimisation of a photocatalytic water treatment using Response Surface Methodology and Quality by Design approach
}

\begin{abstract}
Many water treatments methods have been developed to remove organic pollutants from contaminated waters. Their efficiency is usually assessed by removal measurements and the effect of operational factors on the processe is rarely explored. To bridge this gap, an experimental design methodology has been applied to optimize an advance oxidation process combining adsorption and photocatalysis, using AZURAD® software. This approach was applied to the removing of carbamazepine (CBZ) in aqueous solution by a bio sourced activated carbon and $\mathrm{TiO}_{2}$ composite material under light exposure. Two experimental designs were performed considering three quantitative factors $(\mathrm{pH}$, catalyst dose and temperature) and one qualitative factor (dissolved oxygen concentration). From the response surface methodology (RSM), the optimized operational factors for $\mathrm{CBZ}$ adsorption and degradation were independently determined. Using desirability function approach, common optimized conditions for both process were assessed with a catalyst dose of 0.13 g. $\mathrm{L}^{-1}$, oxygen saturated medium and either $\mathrm{pH}=9.5$ and $\mathrm{T}=40^{\circ} \mathrm{C}$ or $\mathrm{pH}=7.8$ and $\mathrm{T}=10^{\circ} \mathrm{C}$. The Quality by Design approach showed that the experimental conditions could vary maintaining the adsorption and photocatalysis process removal efficiency (with more than 70 and $80 \%$, respectively) with a high probability of $80 \%$. This highlights the robustness of the treatment process and its potential upscaling.
\end{abstract}

Keywords: Optimisation, Response surface method, Desirability function, Adsorption, Photocatalysis, Pharmaceuticals, Wastewater treatment. 


\section{Introduction}

The presence of many pharmaceuticals in wastewater treatment plants (WWTPs) effluents have attracted growing attention. Most processes applied in WWTPs are not effective enough to removepharmaceuticals, and the implementation of advanced tertiary treatments can be very costly [1]. Among pharmaceuticals, carbamazepine (CBZ), an antiepileptic and psychotropic drug, is recalcitrant to traditional biological wastewater treatment technologies [2-4]. Consequently, it is frequently detected in waters (drinking water, groundwater, and surface water). For instance, CBZ has been detected in groundwater and drinking water with a concentration of $610 \mathrm{ng} . \mathrm{L}^{-1}$ and 18 ng. $\mathrm{L}^{-1}$, respectively $[5,6]$. In water, $\mathrm{CBZ}$ is categorized as a pseudo persistent organic pollutant because its removing efficiencies in WWTPs are mostly below 10\%, and it is continuously discharged in wastewater due to its high worldwide production (1014t/y) and consumption $[4,7]$. Furthermore, $\mathrm{CBZ}$ is also toxic to aquatic life, such as bacteria, algae, invertebrates, and bacteria, and its long-term exposure can threaten public health and aquatic ecosystems [1]. Therefore, it is necessary to find an efficient process for the treatment of CBZ in water [5].

Many recent studies focused on the removal of PPs from wastewaters. It is widely accepted that the most commonly available treatment processes such as flocculation, sedimentation, filtration, activated sludge or chlorination, are inappropriate to remove PPs. However, promising ways to remove PPs are offered by new technologies such as activated sludge treatment $[8,9]$, submerged membrane bioreactor [10,11], mixed cultures [12], constructed wetland [13], coagulation [14], membrane bioreactor technology [15], advanced oxidation processes (AOPs) [16-18] and adsorption [19]. But these technologies also have some draw backs. For example, activated carbon adsorption or membrane bioreactor technology processes are very 
expensive and not effective enough to remove organic micropollutants [5,16]. AOPs can produce toxic intermediates or be partially efficient. Thus, the control of treatment's operational parameters is essential to increase the removal of pharmaceuticals from wastewaters and guaranty the safety of WWTPs effluents.

In the literature, this aspect has only been little studied for the removing of PPs by heterogeneous photocatalysis. The simultaneous determination of the major parameters controlling the adsorption and induced degradation process is rarely discussed. Literature data usually evaluates the effect of one or two parameters (most often the nature of the photocatalyst) on the removal of PPs from water, leading it unclear whether the optimal experimental conditions for adsorption and induced degradation were achieved.

In the same time, no information on the effect of the experimental conditions such as $\mathrm{pH}$, temperature or catalyst dose are provided. implicitly suggesting that an optimization is required. For carbamazepine, some authors observed its elimination in the presence of $\mathrm{TiO}_{2}$, synthesized $\mathrm{ZnO}$ nanoparticles or CoMgFe-LDO and peroxymonosulfate in given conditions, and they did not investigate the influence of experimental condition to optimize both adsorption and induced degradation processes $[21,22]$. Sometimes both processes' efficiency is explored by changing the nature of the catalyst. Thus, Nawaz et al. revealed that the graphene oxide/ $\mathrm{TiO}_{2}$ exhibits strong adsorption and photodegradation capacity almost twice as high as naked $\mathrm{TiO}_{2}$, as more than $99 \%$ removal of CBZ is observed [23].

In addition to these classical approaches, other studies investigated the effect of $\mathrm{pH}$ and catalyst dose on the adsorption and degradation step. For instance, Gar Alalm et al., showed the $\mathrm{pH}$ dependency of both processes due to 
the ionization state of the organic compounds, the charge surface of $\mathrm{TiO}_{2}$ and $\mathrm{AC}$, and the production of hydroxyl radicals [24]. In addition, they proved that removing of pharmaceuticals is affected by the catalyst dose with an improvement until a concentration limit and beyond a removal decline due to the decrease of light penetration attributed to higher turbidity. However, even if this approach appears more rigorous with the independent study of additional parameters, other effects like dissolved oxygen concentration or temperature were not taken into account. These latter are of great interest because temperature and oxygen concentration are key parameters in sorption and hole-electron recombination process [25].

Recently, the heterogenous photocatalytic degradation of pharmaceuticals was more rigorously examined by considering the effect of the temperature. Thus, Y. Gu et al. proved that the removal rate of Ibuprofen in the presence of $\mathrm{TiO}_{2-}$ impregnated activated carbon is not clearly modified by the temperature ( 22 to $28^{\circ} \mathrm{C}$ ), the $\mathrm{pH}$ and the composite/Ibuprofen ratio [26]. However, the results of this study showed that the evaluation of the effect of experimental parameters is strongly affected by the limit values (weak scale range) or by the independent parameter approach to reach the best removal efficiency.

To assess more scrupulously the operational parameters in the removal of pollutants from water, experimental design approach based on response surface methodology (RSM) has been recently applied. RSM is a set of statistical and mathematical tools for designing experiments and optimizing the effect process variables on the removal process by reducing the number of experiments [27-29]. Thus, classical factors such as time, $\mathrm{pH}$, initial concentration, dose ( $\mathrm{PP}$ and catalyst), dissolved oxygen concentration and light intensity affecting the 
adsorption and degradation of pharmaceuticals have been successfully investigated [22,30-32]. Nevertheless, some factors such as temperature and dissolved oxygen concentration were rarely considered in the same set of experiments, and generally the response of either adsorption or photocatalytic degradation was taken into account. This suggests that RSM appears sometimes deficient to correctly determine the optimized operational parameters of photocatalytic process.

The main objective of the present article is to optimize adsorption and photocatalysis processes using experimental design. A composite material prepared from Argania Spinosa shells and $\mathrm{TiO}_{2}$ Degussa P25 $\left(\mathrm{AC}-\mathrm{TiO}_{2}\right)$ was used to study $\mathrm{CBZ}$ removal. The effect of $\mathrm{pH}$, temperature, $\mathrm{AC}-\mathrm{TiO}_{2}$ dose and dissolved oxygen concentration were investigated and modelled by RSM. Optimal parameters offering the best compromise between high adsorption and high degradation were determined through desirability function approach. The Quality by Design (QbD) method allows us to determine the variability around the optimized operational values maintaining a good efficiency of both processes to support the upscaling of the treatment.

\section{Material and Methods}

\subsection{Reagent}

Carbamazepine (99\% purity) was purchased from Sigma-Aldrich (St-Louis, USA), and acetonitrile (HPLC grade) was provided by VWR chemicals (Fontenay-sous-Bois, France). Water and acetonitrile (Optima ${ }^{\circledR}$ LC/MS grade) were obtained from Fischer Scientific SAS (Fair Lawn, USA, and Geel, Belgium, respectively) and formic acid (LC/MS grade) was purchased from VWR chemical (Fontenay-sous-Bois, France). 
$\mathrm{TiO}_{2}$ and activated carbon of Argania Spinosa tree nutshells composites used in this paper were prepared and well-characterized (chemically and physically) in a recent work by El Mouchtari et al. [33]. Briefly, the activated carbon was obtained by calcination and $\mathrm{H}_{3} \mathrm{PO}_{4}$ activation and $\mathrm{TiO}_{2}$ Degussa $\mathrm{P} 25$ was fixed on the support by impregnation confirmed by XRD, FTIR, TGA and SEM analysis. The biocomposite contains $9 \%$ of $\mathrm{TiO}_{2}$ particles (size around $24.2 \mathrm{~nm}$ ) and has a specific surface area of $959 \mathrm{~m}^{2} \cdot \mathrm{g}^{-1}$.

Table 1. Structure and physico-chemical properties of Carbamazepine

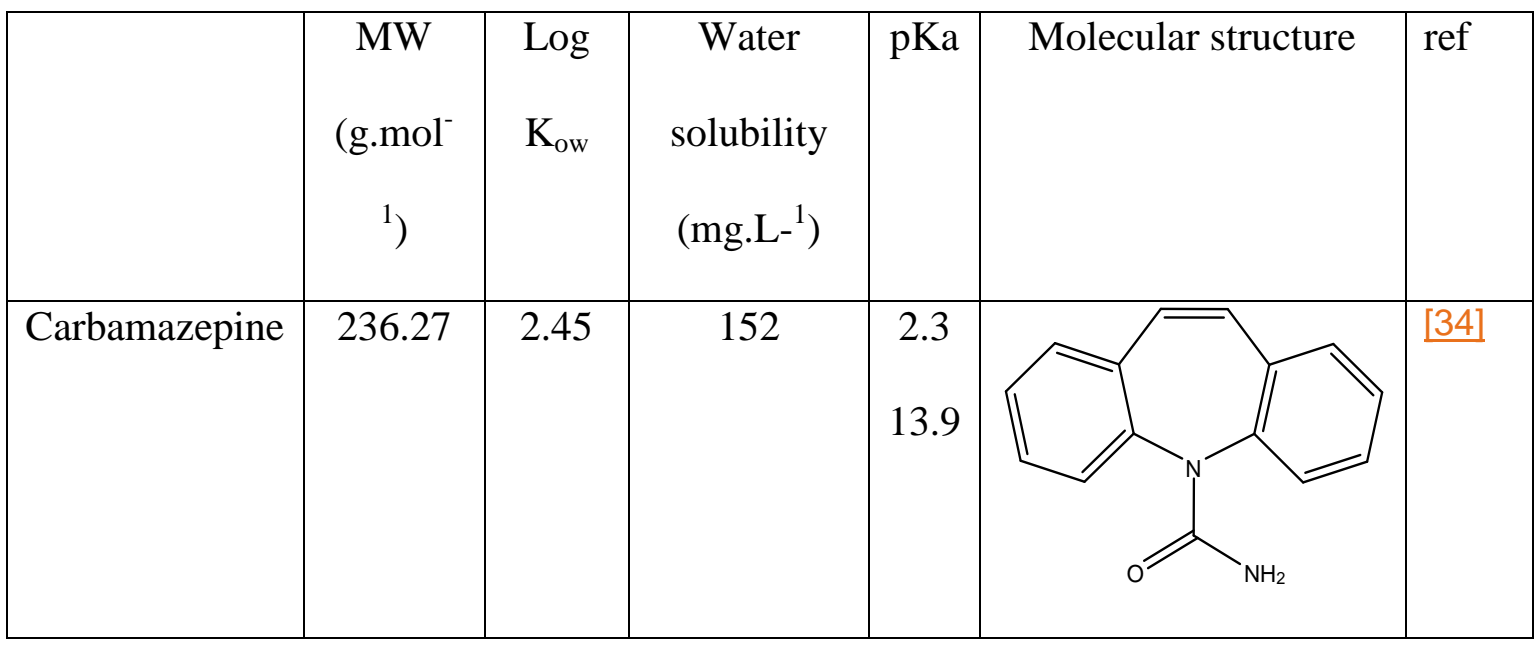

\subsection{Photocatalysis experiments}

Irradiation was realized using a LOT Quantum Design Xenon lamp system (300 W) equipped with a $45^{\circ}$ beam turner whose emission was filtrated by a water and atmospheric filter (LOT Quantum Design LSZ231 and LSZ176) to deliver 290-800 nm wavelength [35]. $50 \mathrm{~mL}$ of the mixture was placed in a batch reactor, and the solution was continuously stirred along the experiment. Sample and reactor were kept at a chosen temperature by a water flow. 


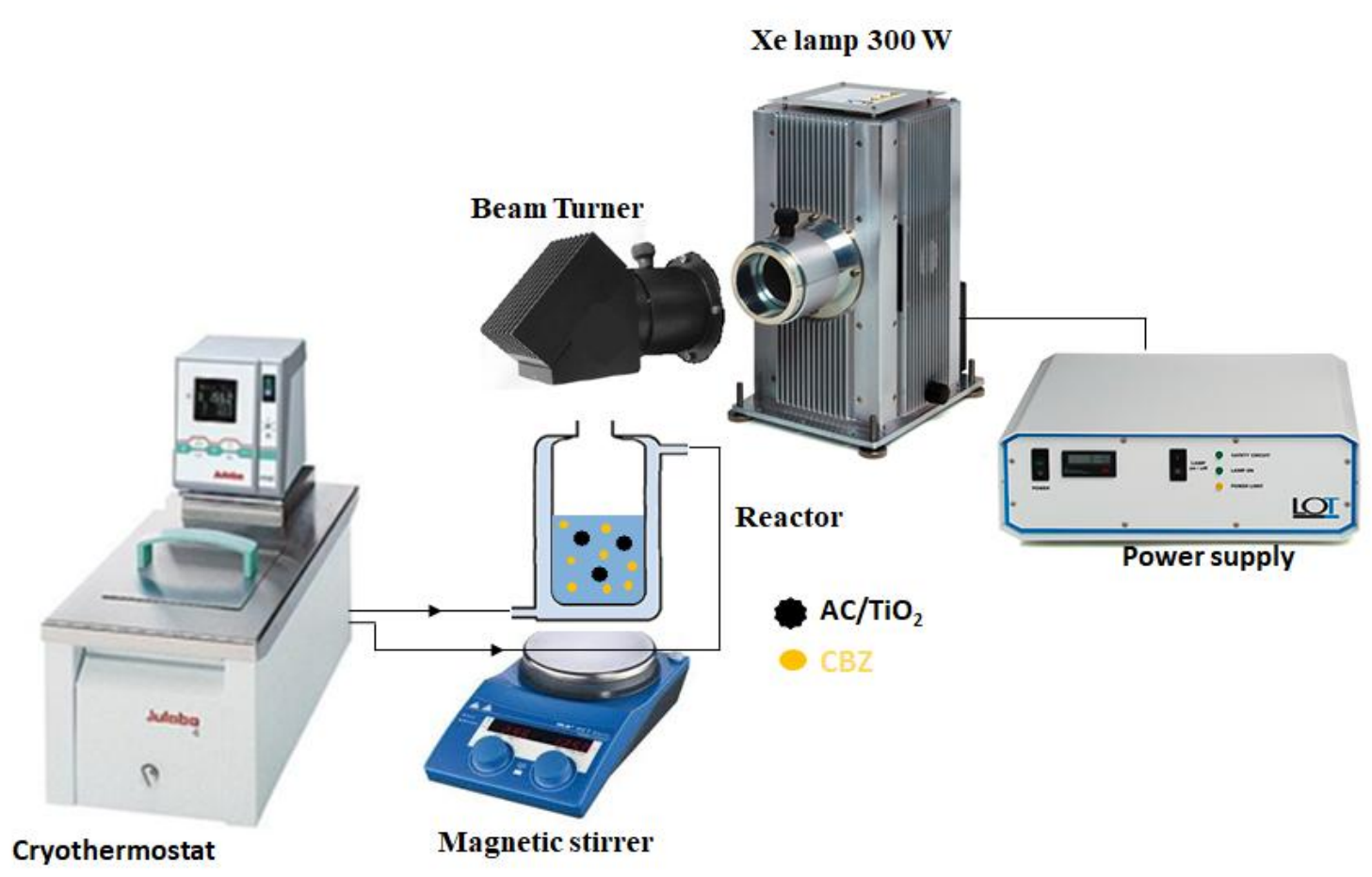

Figure 1. Polychromatic irradiation system

\subsection{HPLC analysis of pharmaceutical product}

The concentration of carbamazepine was determined by liquid chromatography system (UPLC PerkinElmer Altus 30) equipped with an Eclipse Plus C18 column (3.5 $\mu \mathrm{m} ; 2.1$ $\times 150 \mathrm{~mm}$ ) and a 220/240 pump, a 330-diode array UV-visible detector and a 410automatic injector. An isocratic method set at a flow rate of $0.25 \mathrm{~mL} . \mathrm{min}^{-1}$ using a mixture of water/acetonitrile (with $0.1 \%$ formic acid) ratio of $65: 35(\mathrm{v}: \mathrm{v})$. The injected volume was $10 \mu \mathrm{L}$ and the detection of CBZ was realized using a wavelength of 285 $\mathrm{nm}$. Before injection, samples were systematically filtered on a $0.2 \mu \mathrm{m}$ cellulosic filter of $15 \mathrm{~mm}$ in diameter (Agilent Technologies) in order to remove $\mathrm{AC} / \mathrm{TiO}_{2}$ composite. Fresh calibration solutions have been injected within each analytical sequence. A linear calibration was obtained in the range 0.01 to $50 \mathrm{mg} . \mathrm{L}^{-1}$. Linearity of the calibration plot was assumed for $\mathrm{R}^{2}$ values greater than 0,99 . A regular injection of blank samples was performed to control the absence of carryover and cross contamination. 


\subsection{Experimental design}

The main objective of the experimenters is to estimate the current levels of factors that are near to optimum. Indeed, the study is designed to model the percentage of adsorption and degradation (that one seeks to maximize) of carbamazepine in the whole experimental design. For this purpose, two experimental designs (A and $\mathrm{B}$ ) were performed using AZURAD ${ }^{\circledR}$ software. In a preliminary approach, the first experimental design considers two quantitative factors ( $\mathrm{pH}$ and composite concentration $\left[\mathrm{AC} / \mathrm{TiO}_{2}\right]$ ) to optimize $\mathrm{CBZ}$ adsorption and the ratio $\mathrm{CBZ}$ concentration vs biocomposite concentration while the second experimental design took into account three factors, one is qualitative (dissolved oxygen concentration, $\left[\mathrm{O}_{2}\right]$ ) with three levels and two are quantitative factors ( $\mathrm{pH}$ and temperature). The objective of the experimental design $\mathrm{B}$ was to improve both adsorption and degradation processes. The experimental designs and their variables are shown in Table 1.

Table2. Domain of interest for the quantitative variable (X1 and X2) of the experimental design $\mathrm{A}$ and for the qualitative variable (X1') and the quantitative variables (X2' and X3') of the experimental design $\mathrm{B}$

\begin{tabular}{|c|c|c|c|c|c|c|c|}
\hline \multirow{2}{*}{$\begin{array}{c}\text { Experimental } \\
\text { design }\end{array}$} & \multirow[t]{2}{*}{ Variable } & \multirow[t]{2}{*}{ Factor } & \multirow[t]{2}{*}{ Unit } & \multicolumn{2}{|c|}{ Qualitative factor } & \multicolumn{2}{|c|}{ Quantitative factors } \\
\hline & & & & $\begin{array}{l}\text { Number } \\
\text { of levels }\end{array}$ & Level & Centre & $\begin{array}{c}\text { Variation } \\
\text { step }\end{array}$ \\
\hline \multirow{2}{*}{ A } & $\mathrm{X}_{1}$ & $\mathrm{pH}$ & & & & 7.0 & 3.0 \\
\hline & $\mathrm{X}_{2}$ & {$\left[\mathrm{AC} / \mathrm{TiO}_{2}\right]$} & g.. $\mathrm{L}^{-1}$ & & & 0.13 & 0.07 \\
\hline B & $\mathrm{X}_{1}^{\prime}$ & {$\left[\mathrm{O}_{2}\right]$} & & 3 & $\begin{array}{c}\text { Low } \\
\text { Middle } \\
\text { High }\end{array}$ & & \\
\hline
\end{tabular}




\begin{tabular}{|c|c|c|c|c|c|}
\hline & $\mathrm{X}_{2}^{\prime}$ & $\mathrm{pH}$ & & 7.0 & 3.0 \\
\cline { 2 - 6 } & $\mathrm{X}_{3}^{\prime}$ & $\mathrm{T}$ & ${ }^{\circ} \mathrm{C}$ & 25.0 & 15.0 \\
\hline
\end{tabular}

The three levels of oxygen concentration were achieved as followed: low $\left[\mathrm{O}_{2}\right](<$ $1.0 \times 10^{-5} \mathrm{~mol} . \mathrm{L}^{-1}$ ) was obtained by the deoxygenation of the solution through bubbling with nitrogen $(50 \mathrm{~mL}$ solution is deoxygenated for $10 \mathrm{~min}$ before experiment and all along the experiment), middle $\left[\mathrm{O}_{2}\right] \approx 2.64 \times 10^{-4}$ mol. $\mathrm{L}^{-1}$ corresponds to the typical concentration of oxygen in aqueous solution and high $\left[\mathrm{O}_{2}\right] \approx 1.29 \times 10^{-3}$ mol. $\mathrm{L}^{-1}$ was reached by the oxygenation of the solution through bubbling with oxygen $(50 \mathrm{~mL}$ solution is oxygenated for $10 \mathrm{~min}$ before experiment and all along the experiment) [37].

\subsection{Application in WWTP effluents}

Removal of CBZ in optimal conditions was compared in ultrapure water and in an effluent water collected in La Pioline WWTP (Aix-en Provence). During both experiments, $\mathrm{CBZ}$ concentration was $25 \mathrm{mg} \cdot \mathrm{L}^{-1}$, and $\mathrm{AC} / \mathrm{TiO}_{2}$ was fixed to $0.13 \mathrm{mg} \cdot \mathrm{L}^{-1}$. The termprature of the experiment was controlled to $10^{\circ} \mathrm{C}$ under oxygen bubbling. $\mathrm{pH}$ was adjusted to 7.8 by addition of $\mathrm{HCl}$ or $\mathrm{NaOH}$. Batch experiments were conducted as described in section 2.2.3. Results and discussion

\subsection{Experimental design $A$}

\subsubsection{The effect of initial $\mathrm{pH}$ and $\mathrm{AC}$-TiO2 dose on $\mathrm{CBZ}$ adsorption}

The purpose of this preliminary study is to model the percentage of adsorption as a function of $\mathrm{pH}$ and concentration of the $\mathrm{AC}-\mathrm{TiO}_{2}$ composite material. Based on the experimental domain presented in the table 1 , we used a polynomial model of degree 2 , which can be written as:

$$
\mathrm{Y}=\mathrm{b}_{0}+\mathrm{b}_{1} \times \mathrm{X}_{1}+\mathrm{b}_{2} \times \mathrm{X}_{2}+\mathrm{b}_{11} \times \mathrm{X}^{2}{ }_{1}+\mathrm{b}_{22} \times \mathrm{X}^{2}{ }_{2}+\mathrm{b}_{12} \times \mathrm{X}_{1} \mathrm{X}_{2}
$$


To better estimate the coefficients $b_{0}, b_{1}, b_{2}, b_{11}, b_{22}$ and $b_{12}$ of the model and to be able to use it for predictive purposes throughout the experimental field of interest 3639], we have realized a composite design with 9 experiments (Exp). Experiment 9 was repeated thrice to quantify the experimental variability. The experimental conditions and CBZ adsorption percentage are presented in Table 2.

Table 3. Experimental design conditions and CBZ adsorption (Y) $[\mathrm{CBZ}]=25 \mathrm{mg} \cdot \mathrm{L}^{-1}$, $\mathrm{T}=25^{\circ} \mathrm{C}$ and oxygenated condition

\begin{tabular}{|c|c|c|c|}
\hline $\mathbf{E x p}$ & $\mathbf{p H}$ & {$\left[\mathrm{AC}-\mathbf{T i O}_{\mathbf{2}} \mathbf{~ g . ~}^{\mathbf{- 1}}\right.$} & $\mathbf{Y}(\mathbf{\%}$ of CBZ adsorption) \\
\hline $\mathbf{1}$ & 4 & 0.06 & 39.1 \\
\hline $\mathbf{2}$ & 10 & 0.06 & 41.4 \\
\hline $\mathbf{3}$ & 4 & 0.20 & 86.4 \\
\hline $\mathbf{4}$ & 10 & 0.20 & 91.6 \\
\hline $\mathbf{5}$ & 4 & 0.13 & 72.3 \\
\hline $\mathbf{6}$ & 10 & 0.13 & 78.3 \\
\hline $\mathbf{7}$ & 7 & 0.06 & 43.9 \\
\hline $\mathbf{8}$ & 7 & 0.20 & 91.7 \\
\hline $\mathbf{9}$ & 7 & 0.13 & 80.1 \\
\hline $\mathbf{9}$ & 7 & 0.13 & 72.3 \\
\hline $\mathbf{9}$ & 7 & 0.13 & 71.4 \\
\hline & & & \\
\hline
\end{tabular}

From the experimental results, the estimation of the model coefficients has been calculated using multi-linear regression and are presented in the following equation 2 :

$$
\mathrm{Y}=75.41+2.26 \times \mathrm{X}_{1}+24.21 \times \mathrm{X}_{2}-1.32 \times \mathrm{X}^{2}{ }_{1}-8.86 \times \mathrm{X}^{2}{ }_{2}+0.74 \times \mathrm{X}_{1} \mathrm{X}_{2}
$$

To validate the postulated model, ANOVA test was used, and the results are gathered in supplemental material (Table S1). The deviations from the quadratic 
regression are not significant $(\mathrm{p}$-value $=90.9 \%)$ and the regression is very significant $(\mathrm{p}$-value $=0.0143 \%)$. This supports the model and allows to use it to make prediction throughout the experimental domain $[40,41]$.

Thus, $\mathrm{CBZ}$ adsorption response was plotted as a function of $\mathrm{pH}$ and $\mathrm{AC}-\mathrm{TiO}_{2}$ concentration as presented in Figure 2. It can be observed that the variation of the response is independent of the $\mathrm{pH}$ in the domain between 4.0 and 10.0 while the factor "AC- $\mathrm{TiO}_{2}$ dose" significantly affects the variation in $\mathrm{CBZ}$ adsorption. $\mathrm{CBZ}$ adsorption is improved with the increase of $\mathrm{AC}-\mathrm{TiO}_{2}$ concentration. Adsorption higher than $90 \%$, was achieved with a dose of $\mathrm{AC}-\mathrm{TiO}_{2}$ of $0.2 \mathrm{~g} . \mathrm{L}^{-1}$, without any effect of the $\mathrm{pH}$.

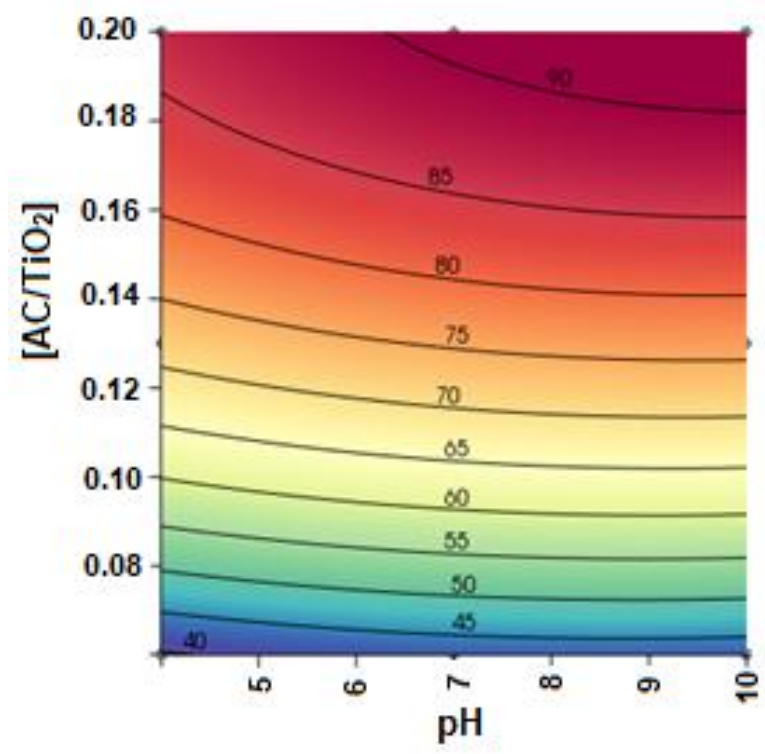

Figure 2. Response surface plot of $\mathrm{CBZ}$ adsorption as the function of $\mathrm{pH}$ and $\mathrm{AC}-\mathrm{TiO}_{2}$ concentration, $[\mathrm{CBZ}]=25 \mathrm{mg} \cdot \mathrm{L}^{-1}, \mathrm{~T}=25^{\circ} \mathrm{C}$ and oxygenated condition

The $\mathrm{pH}$ independency means that on this $\mathrm{pH}$ scale, neither the composite and neither CBZ is affected i.e. no change in the surface charge and in the molecular form (protonated or not) occur, respectively. This is in accordance with the high pKa value of CBZ around 14 [42].

This preliminary study shows that $\mathrm{CBZ}$ adsorption on $\mathrm{AC}-\mathrm{TiO}_{2}$ composite is only controlled by $\mathrm{CBZ} / \mathrm{AC}-\mathrm{TiO}_{2}$ concentration ratio, highlighting that both processes 
(adsorption and photocatalysis) should be considered at the same time in an experimental design.

\subsection{Experimental design B}

\subsubsection{Optimization of CBZ adsorption and degradation}

$\mathrm{CBZ} / \mathrm{AC}-\mathrm{TiO}_{2}$ concentration ratio was chosen as a constant with concentrations of 25 mg.L ${ }^{-1}$ and 0.1 g.L ${ }^{-1}$, respectively, as a compromise condition that allows a partial and significant CBZ adsorption onto the biocomposite.

Mathematical modeling : the qualitative variable was studied using a model (absence presence) of the form:

$$
\mathrm{Y}=\mathrm{b}_{0}+\mathrm{b}_{1 \mathrm{~A}} \mathrm{X}_{1 \mathrm{~A}}^{\prime}+\mathrm{b}_{1 \mathrm{~B}} \mathrm{X}_{1 \mathrm{~B}}^{\prime}
$$

where $X_{1 \mathrm{~A}}^{\prime}$ and $\mathrm{X}_{1 \mathrm{~B}}^{\prime}=0$ or 1 in function of the present level. $\mathrm{b}_{1 \mathrm{~A}}$ and $\mathrm{b}_{1 \mathrm{~B}}$ represent the variation of the response when the oxygen concentration factor changes from level 3 to level 1 and 2, respectively.

For the two quantitative variables, different types of models can relate the variation of the response to the variation of the input parameters. The most used models are polynomial models, more particularly of degree 2 , because they make it possible to consider possible curvatures in the domain or possible torsions of the surface of answers. In this study, we used a second-order polynomial model, which can be written as:

$$
\mathrm{Y}=\mathrm{b}_{0}+\mathrm{b}_{2} \mathrm{X}_{2}^{\prime}+\mathrm{b}_{3} \mathrm{X}_{3}{ }_{3}+\mathrm{b}_{22} \mathrm{X}_{2}^{\prime 2}+\mathrm{b}_{33} \mathrm{X}^{\prime 2}{ }_{3}+\mathrm{b}_{23} \mathrm{X}_{2} \mathrm{X}_{3}^{\prime}
$$

Finally, the final model is an additive model. The complete equation can be written:

$$
Y=b_{0}+b_{1 A} X_{1 A}^{\prime}+b_{1 B} X_{1 B}^{\prime}+b_{2} X_{2}^{\prime}+b_{3} X_{3}^{\prime}+b_{22} X^{\prime 2}{ }_{2}+b_{33} X^{\prime 2}{ }_{3}+b_{23} X_{2}^{\prime} X_{3}^{\prime}
$$


In order to estimate the coefficients of this mathematical model, experiments were carefully chosen since a "classical" design of experiments could not be used. So the experimental domain of interest was covered with a set of possible experiments, called candidate points and then 14 experiments presented in Table 3 were selected using exchange algorithm based on D-optimality criteria. The experiments 12 and 14 have been repeated respectively two and three times in order to calculate the experimental variance.

The experimental design, is presented in Table 3, describing the set of experimental conditions for each experiment. The 20 experiments are done in a random order.

Table 4: Experimental design and results for the two response $\mathrm{Y}_{1}$ (\% degradation) and $\mathrm{Y}_{2}$ (\% adsorption).

\begin{tabular}{|c|c|c|c|c|c|}
\hline $\mathrm{N}^{\circ} \operatorname{Exp}$ & {$\left[\mathrm{O}_{2}\right]$} & $\mathrm{pH}$ & $\mathrm{T}\left({ }^{\circ} \mathrm{C}\right)$ & $\mathrm{Y}_{1}(\%)$ & $\mathrm{Y}_{2}(\%)$ \\
\hline 1 & Low & 4.0 & 40.0 & 42.111 & 72.592 \\
\hline 2 & Low & 10.0 & 40.0 & 52.773 & 70.343 \\
\hline 3 & Low & 10.0 & 25.0 & 59.848 & 74.816 \\
\hline 4 & Low & 7.0 & 10.0 & 66.668 & 74.008 \\
\hline 5 & Medium & 4.0 & 10.0 & 65.807 & 80.242 \\
\hline 6 & Medium & 10.0 & 10.0 & 73.731 & 80.688 \\
\hline 7 & Medium & 4.0 & 25.0 & 65.560 & 79.161 \\
\hline 8 & Medium & 7.0 & 40.0 & 78.076 & 69.425 \\
\hline 9 & High & 4.0 & 10.0 & 78.537 & 82.781 \\
\hline 10 & High & 10.0 & 10.0 & 83.662 & 82.122 \\
\hline 11 & High & 4.0 & 40.0 & 76.122 & 70.343 \\
\hline 12 & High & 10.0 & 40.0 & 95.498 & 74.892 \\
\hline 12 & High & 10.0 & 40.0 & 98.240 & 73.778 \\
\hline 13 & High & 7.0 & 25.0 & 86.510 & 77.142 \\
\hline 14 & Medium & 7.0 & 25.0 & 65.355 & 76.800 \\
\hline
\end{tabular}




\begin{tabular}{|c|c|c|c|c|c|}
\hline 14 & Medium & 7.0 & 25.0 & 66.639 & 76.496 \\
\hline $14 "$ & Medium & 7.0 & 25.0 & 68.992 & 75.061 \\
\hline
\end{tabular}

\subsubsection{Validation of the model}

The estimation of the model coefficient with all the experiments was calculated using multi-linear regression for CBZ degradation and adsorption, respectively:

$\mathrm{Y}_{1}=86.4-31.2 \mathrm{X}_{1 \mathrm{~A}}^{\prime}-15.76 \mathrm{X}_{1 \mathrm{~B}}^{\prime}+5.8 \mathrm{X}_{2}^{\prime}-0.31 \mathrm{X}_{3}^{\prime}-5.64 \mathrm{X}_{2}^{\prime 2}+4.01 \mathrm{X}_{3}^{\prime 2}+2.77 \mathrm{X}_{2}^{\prime} \mathrm{X}_{3}^{\prime}$

$\mathrm{Y}_{2}=76.62-3.44 \mathrm{X}_{1 \mathrm{~A}}^{\prime}-0.77 \mathrm{X}_{1 \mathrm{~B}}^{\prime}+0.022 \mathrm{X}_{2}^{\prime}-3.97 \mathrm{X}_{3}^{\prime}+3.13 \mathrm{X}_{2}^{\prime 2}-2.14 \mathrm{X}^{\prime 2}{ }_{3}+0.29 \mathrm{X}_{2}^{\prime} \mathrm{X}_{3}^{\prime}$

Where, $\mathrm{Y}_{1}$ response is the percentage of degradation and $\mathrm{Y}_{2}$ response is the percentage of adsorption.

Analysis of variance was used to check the significance and adequacy of the model (supplemental material, Table S2). The degree of significance and accuracy of the regression model were evaluated using $\mathrm{p}$-value, and $\mathrm{R}^{2}$ [43-46]. The variance was calculated from the three replicates realized on the central point of the matrix (experiments: 12, 12' and 14, 14', 14") and which is respectively 2.27 and 0.86 for the percentage of adsorption and degradation. It shows a very good repeatability of the measurements. Thus, the variation of the results depends only on the variation of the factors in the design and not on the experimentation. A very high F-value and a very low probability value $(<0.05)$ for $\mathrm{CBZ}$ adsorption and degradation indicating that the model obtained was highly significant [47-50]. How well the estimated model fits the data can be measured by the value of $R^{2}$, which lies between 0 and 1 . When $R^{2}$ value is closer to 1 , the better estimation of regression equation fits the sample data. $R^{2}$ value of 
0.90 and 0.88 are obtained for adsorption and degradation respectively (presented in table S2), suggested that the estimated regression equations can be used to predict the percentages of adsorption and degradation of CBZ within the experimental range.

Moreover, most of the residues (difference between the experimental value and the predicted value) are close to zero and are randomly distributed on either side of the axis, which allows the model to be validated (Supplemental material, figure S1).

\subsubsection{Interpretation of response surfaces for CBZ degradation}

The 2-D response surface plot is a graphical illustration used to explain the resolution of regression model equation used to determine optimum levels of factors. It is used to understand the type of interactions between variables in order to enhance the process treatment efficiency.

The variation in the percentage of degradation response as a function of the values taken by the two factors is shown in the figure 3 for the three levels of dissolved oxygen concentration.

For a low oxygen concentration (figure 3-a), the shape of the response surface highlights a strong variation in the degradation percentage as a function of $\mathrm{pH}$ : $\mathrm{CBZ}$ degradation increases up to a $\mathrm{pH}$ value of 8 , the slight decrease is observed for $\mathrm{pH}>8$ For instance, at $25^{\circ} \mathrm{C}$, a degradation percentage of about $49 \%$ is obtained for a $\mathrm{pH}$ of 5 and this percentage increases to reach $56 \%$ for a $\mathrm{pH}$ of 7 . Regarding the temperature, the response surface curves shows a small variation in the experimental response (when the $\mathrm{pH}$ values are between 4 and 7). If we look at the results at $\mathrm{pH}=4$, the degradation percentage is $51 \%, 46 \%, 44 \%$ and $45 \%$ when the experiments are performed at $10^{\circ} \mathrm{C}$, $20^{\circ} \mathrm{C}, 30^{\circ} \mathrm{C}$ and $40^{\circ} \mathrm{C}$, respectively. However, for $\mathrm{pH}$ values between 7 and 10 , there are greater variations with temperature. Indeed, for a given $\mathrm{pH}$ value, there is a decrease in response as a function of temperature (for temperature values between 0 and $25^{\circ} \mathrm{C}$ ). On 
the other hand, above $25^{\circ} \mathrm{C}$ and for a given $\mathrm{pH}$ value (between 7 and 10), $\mathrm{CBZ}$ degradation increases with the temperature. For example, for a $\mathrm{pH}$ value of 7 , we observe a $55 \%$ degradation response for a temperature of $25^{\circ} \mathrm{C}$ and $59 \%$ at $40^{\circ} \mathrm{C}$.

For medium (figure 3-b) and high (figure 3-c) oxygen concentrations, we observe the same shape of iso-response curves as previously discussed at low oxygen concentration. That means that the same variation of $\mathrm{CBZ}$ degradation with $\mathrm{pH}$ and temperature values is observed.

Nonetheless, there is an increase in the value of the response obtained as a function of the oxygen concentration.

Indeed, in an oxygen saturated medium, $86 \%$ of degradation is obtained for a $\mathrm{pH}$ of 7 and a temperature of $25^{\circ} \mathrm{C}$, but in an aerated and deaerated medium with the same temperature and $\mathrm{pH}$ conditions, $71 \%$ and $55 \%$ of degradation are respectively obtained. These results are illustrated in Supplemental material (figure S2).

(a)

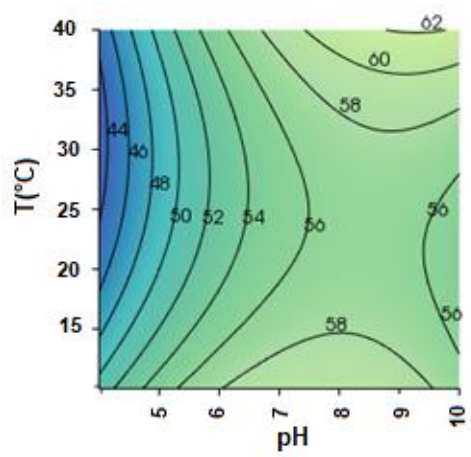

(b)

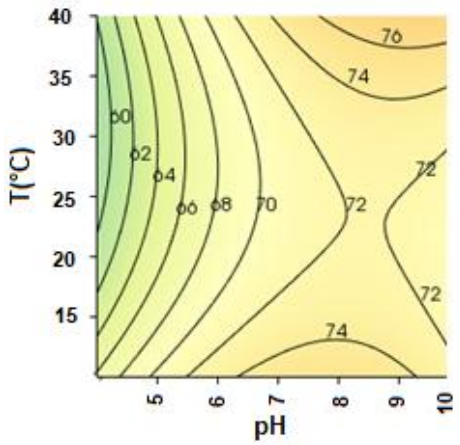

(c)

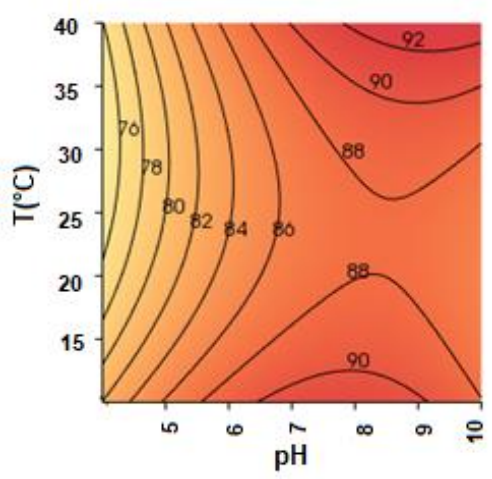

Figure 3: Response surface plot of $\mathrm{CBZ}$ degradation as the function of $\mathrm{pH}$, temperature and fixed factors: (a) deaerated medium (b) aerated medium and (c) oxygen saturated medium

The results of these curves show that to reach the optimum, we should select a temperature between 10 and $25^{\circ} \mathrm{C}$, a $\mathrm{pH}$ value between 7 and 10 and a high 
concentration of oxygen. Firstly, the effect of the temperature can be explained by the temperature dependency of $\mathrm{CBZ}$ sorption; high temperature restraining its adsorption and then limiting its degradation by surface reactive species [51]. Secondly, the presence of a large quantity of dissolved oxygen may slow down electron-hole recombination on $\mathrm{TiO}_{2}$ surface, increasing consequently the efficiency of the composite material [52,53]. Moreover, high concentration of $\mathrm{O}_{2}$ could favor its reduction by generated electron in the conduction band giving rise to $\mathrm{O}_{2}{ }^{--}$[54-55]. These superoxide radical anions could promote the formation of hydroxyl radicals that can induce CBZ degradation [56]. Lastly, the change from neutral to alkaline conditions implies the presence in large amount of $\mathrm{OH}^{-}$ions that can react with positive holes in the valence band to produce hydroxyl radicals $[57,58]$ and then improve CBZ transformation.

\subsubsection{Interpretation of response surfaces for CBZ adsorption}

Similarly, surface plots presented in figure 4 show the variation in CBZ adsorption percentage with influencing factors $\left(\mathrm{pH}\right.$, temperature, $\mathrm{O}_{2}$ concentration). This was carried out through a quantitative response study. From the iso-response curves, the three curves look almost identical and have similar adsorption percentages, which implies that the variation in response is oxygen concentration independent.

Moreover, it is possible to note a non-negligible influence of the temperature on the adsorption of CBZ. When the temperature increases from 25 to $40^{\circ} \mathrm{C}$, a decrease in the response is observed, independently of the $\mathrm{pH}$ value (figure 4-a). For example, for a low oxygen concentration and a $\mathrm{pH}$ value of 4.5 , we obtain an adsorption percentage of about $70 \%$ at $40^{\circ} \mathrm{C}$, whereas this adsorption efficiency is about $76 \%$ at $25^{\circ} \mathrm{C}$. This decrease in adsorption is due to the displacement of the adsorption-desorption equilibrium of carbamazepine at the surface of the composite material, its desorption 
being favored at higher temperatures [59]. In contrast, temperature no longer has a significant effect when working below $25^{\circ} \mathrm{C}$.

So, to maximize adsorption, the temperature should be taken between 10 and $25^{\circ} \mathrm{C}$, the $\mathrm{pH}$ at low values and the oxygen concentration unspecified.

(a)

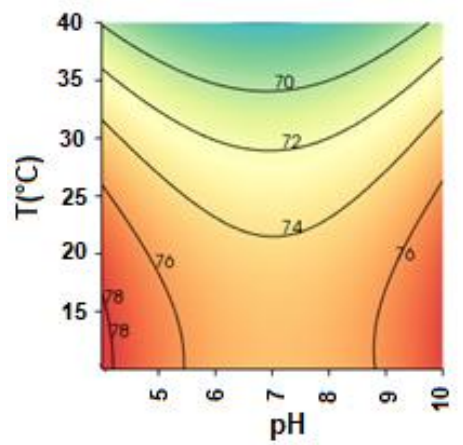

(b)

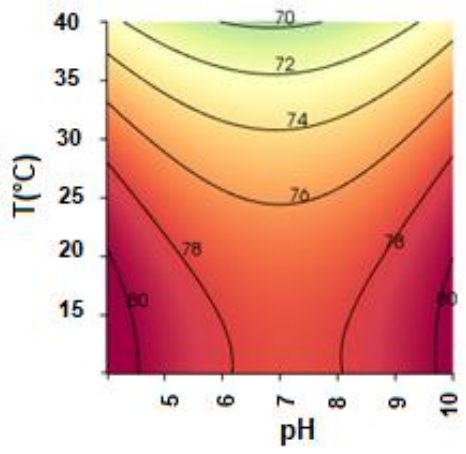

(c)

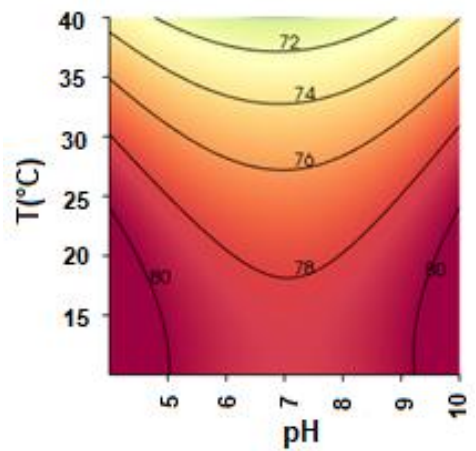

Figure 4: Response surface plot of $\mathrm{CBZ}$ adsorption as a function of $\mathrm{pH}$, temperature and fixed factors: (a) deaerated medium (b) aerated medium and (c) oxygen saturated medium

The decrease in adsorption with the temperature is again attributed to a shift in CBZ adsorption-desorption equilibrium on the composite material surface, the desorption being favored at temperatures above $25^{\circ} \mathrm{C}$ [51]. It can be noticed that $\mathrm{pH}$ has a negligible effect on $\mathrm{CBZ}$ adsorption, despite higher adsorptions at extreme $\mathrm{pH}$, with variations of less than $3 \%$ whatever the other experimental conditions. This is attributed 
to the unchanged surface charge of $\mathrm{CBZ}$ and $\mathrm{CA} / \mathrm{TiO}_{2}$ in our experimental conditions $(4 \leq \mathrm{pH} \leq 10)$. In fact, $\mathrm{AC} / \mathrm{TiO}_{2}$ has an apparent negative surface charge, considering its measured point zero charge of 1 , and CBZ is mainly under its neutral form, considering its two extreme pKa values of 2.3 and 13.9 [60].

\subsubsection{Interpretation of the desirability}

As the conclusions drawn from the experimental design leads to contradictory level of the influencing factors, a desirability approach was carried out to find the best compromise. In any point of the domain, predicted response values have been transformed into a desirability function representing the degree of satisfaction.

To maximize the percentage of adsorption and degradation, two curves of the desirability function have plotted : the desirability functions $d_{1}$ and $d_{2}$ have been set at $0 \%$ when the responses are unacceptable (percentage of degradation $<80 \%$ and percentage of adsorption $<70 \%$ ) and at $100 \%$ when theses percentages are $100 \%$ (desired values). Partial desirability functions $d_{i}$ are represented in Supplementary data (Figure S3).

The overall desirability is calculated within the experimental domain, by equation 8:

$$
\mathrm{D}=\left(\mathrm{d}_{1} \times \mathrm{d}_{2}\right)^{1 / 2}
$$

with $d_{i}=0 \%, d_{i}=100 \%, 0 \%<$ di $<100 \%$ for respectively undesirable, desirable and acceptable values of the response i. Threshold values were selected as follow: $80 \%$ of degradation $70 \%$ of adsorption are required, as below these levels it was considered that the resulting process would provide a to low removal of pollutants. When an undesirable value is obtained for one response (percentage of degradation $<80 \%$ or percentage of adsorption < 70\%), the overall desirable value $\mathrm{D}$ is $0 \%$ and no 
compromise has been found. On the contrary, when each requirement gets completely satisfied, the overall desirability value is $100 \%$. Finally, when $0 \%<\mathrm{D}<100 \%$, an acceptable compromise between the different responses has been found. The response surface corresponding to the compromise zone is presented in Figure 5.

(a)

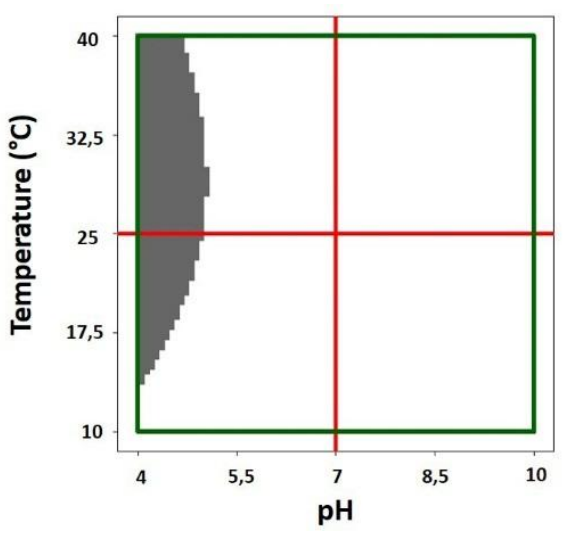

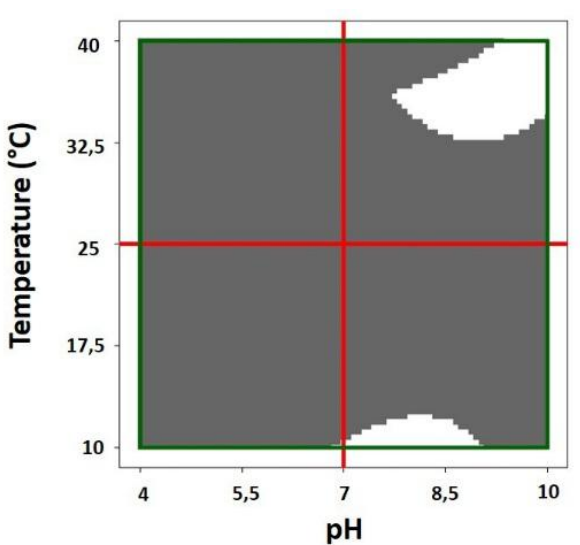

Figure 5. (a) Desirability graph, (b) Design Space obtained by reliability method ( $\operatorname{Pr}(\%$ of degradation $>80 \%)=0.80$ and $\operatorname{Pr}(\%$ of adsorption $>70 \%)=0.80$. The grey area is corresponding to experimental conditions where at least one response is not satisfied (D $=0 \%$ ), the white area is corresponding to $0 \%<\mathrm{D}<100 \%$.

The desirability function is maximized for a temperature of $40{ }^{\circ} \mathrm{C}, \mathrm{pH}=9.5$ and oxygen saturated medium allowing $74 \%$ of adsorption and $92 \%$ of degradation. Another optimal point was found at $10^{\circ} \mathrm{C}, \mathrm{pH}=7.8$ and in oxygen saturated medium allowing $79 \%$ of adsorption and $90 \%$ of degradation. The desirability aera (D > 0\%) can be refined to a smaller area with reliable results, called design space (DS) using Quality by Design (QbD approach [61]). This DS is defined as the multidimensional combination of the two factors in which the objectives will be reached with a fixed probability. More precisely, a confidence interval is constructed, at each point of the compromise zone, for the two responses (percentage of degradation and adsorption) in order to consider experimental and prediction errors. In the DS, all the factors can vary with the certainty that Probability $(\%$ of degradation $>80 \%)=0.80$ and Probability $(\%$ of adsorption $>70 \%)=0.80$ [62-63]. In our case, the area is very small compared to the 
desirability area, but we can observe that the two optimum conditions are conserved [64].

\subsubsection{Application in wastewater}

To validate the removal efficiency of this composite material in field conditions, two experiments were performed in parallel: the first in effluent water from a wastewater treatment plant and the second in ultrapure water. The experimental parameters were fixed to optimize the removal of CBZ as it was demonstrated in the desirability study for $\mathrm{CA} / \mathrm{TiO}_{2}-9 \%$ P25: temperature of $10^{\circ} \mathrm{C}, \mathrm{pH}$ of 7.8 , and super oxygenated medium.

The photodegradation of CBZ was performed after stirring for 2 hours in the dark to allow the adsorption/desorption equilibrium to be reached. At the end of this period, the removal of 81 and $71 \%$ of CBZ from pure water and wastewater effluent, respectively, can be observed by the adsorption process in the presence of $\mathrm{CA} / \mathrm{TiO}_{2}-9 \%$ P25 (see Figure 6). This difference is explained by the fact that the WWTP water undoubtedly contains other adsorbed compounds on the material, which thereby limits the adsorption of CBZ.

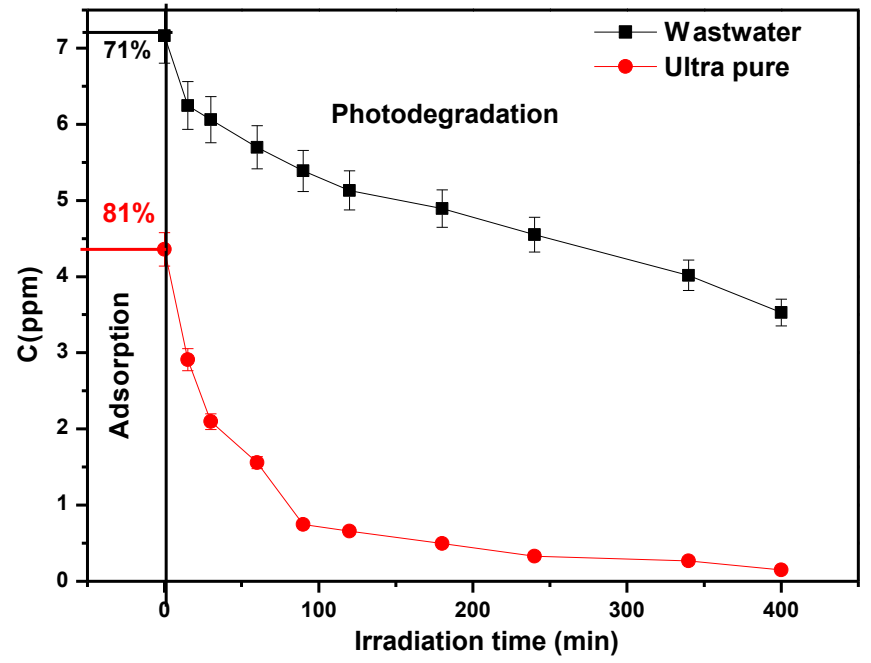


Figure 6. Degradation kinetics of $\mathrm{CBZ}$ in the presence of $\mathrm{CA} / \mathrm{TiO2}-\mathrm{P25}$ in wastewater

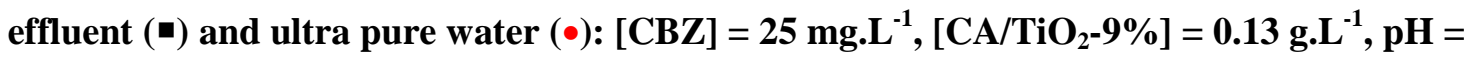
7.8, $\mathrm{T}=10^{\circ} \mathrm{C}, 300 \mathrm{~W}$ Xe lamp, $\left[\mathrm{O}_{2}\right]=$ High.

Under irradiation, sampling at different time intervals of the aqueous phase allowed to establish the disappearance kinetics of $\mathrm{CBZ}$ as presented in Figure 6. It is possible to see that CBZ disappears in both media but with different degrees of progress under irradiation: its elimination is total in ultrapure water after $400 \mathrm{~min}$ of exposure and partial in WWTP water (49\% of CBZ not adsorbed). Nevertheless, as the initial quantities of $\mathrm{CBZ}$ present in the aqueous phase after the adsorption process vary according to the media, the disappearance of CBZ after the same irradiation time in each medium is less significantly different $(3.63 \mathrm{mg} / \mathrm{L}$ in WWTP water versus 4.21 $\mathrm{mg} / \mathrm{L}$ in ultrapure water). Several phenomena allow justifying these distinct kinetics: the induced degradation of adsorbed products which limits that of CBZ, and the presence of dissolved organic matter, which exerts a shielding effect on the $\mathrm{TiO}_{2}$ [65].

Finally, these results show that removal of CBZ from wastewater treatment effluents is possible with approximately $86 \%$ disappearance after $400 \mathrm{~min}$ of exposure through adsorption and photodegradation processes.

\section{Conclusion}

The experimental design approach based on RSM methodology and the desirability function allowed to determine optimized operational conditions for organic compound adsorption and degradation in the presence of a photocatalyst. The removal of carbamazepine was maximised in a temperature range of 10 to $25^{\circ} \mathrm{C}$; a low $\mathrm{pH}$ maximised the adsorption on the biocomposite,; and $\mathrm{pH}>7$, and oxygen saturated medium maximised its degradation. The desirability functions were drawn with a percentage of adsorption and degradation higher than 70 and $80 \%$, respectively. Thus, two operational conditions were obtained: oxygen saturated medium and either $\mathrm{T}=$ $40^{\circ} \mathrm{C}$ and $\mathrm{pH}=9.5$ or $\mathrm{T}=10^{\circ} \mathrm{C}$ and $\mathrm{pH}=7.8$. 
Furthermore, the design space DS obtained by QbD approach demonstrate that the treatment should preserved a high efficiency by modifying operational factors $(\mathrm{T}$ and $\mathrm{pH}$ ) around their optimized values with a high probability (80\%). Thus, CBZ adsorption and degradation remained higher than 70 and $80 \%$, respectively, either with $33.6^{\circ} \mathrm{C} \leq \mathrm{T} \leq 37^{\circ} \mathrm{C}$ and $8.3 \leq \mathrm{pH} \leq 9.7$ or $10^{\circ} \mathrm{C} \leq \mathrm{T} \leq 11.5^{\circ} \mathrm{C}$ and $7.4 £ \mathrm{pH} £ 8.6$.

Finally, the design space DS obtained by QbD approach demonstrated that the treatment should preserved a high efficiency by modifying operational factors. This could usefully help the upscaling of the water treatment by the determination of the robustness of the process that is crucial for a wastewater treatment plant.

\section{References}

[1] Y. Yang, Y.S. Ok, K.-H. Kim, E.E. Kwon, Y.F., Sci. Total Environ. 596-597 303-320 (2017). doi :10.1016/j.scitotenv.2017.04.102.

[2] M. Clara, B. Strenn, N. Kreuzinger, Water Res. 38 947-954 (2004)10.1016/j.watres.2003.10.058.

[3] K. Wang, T. Larkin, N. Singhal, Y. Song, Sci. Total Environ. 624 1263-1273 (2018). doi : 10.1016/j.scitotenv.2017.12.243.

[4] Y. Zhang, S.-U. Geißen, C. Gal, chemosphere. 73 1151-1161 (2008). doi: 10.1016/j.chemosphere.2008.07.086.

[5] K. Gurung, M.C. Ncibi, M. Shestakova, M. Sillanpää, Appl. Catal. B Environ. 221 329-338 (2018). doi:10.1016/j.apcatb.2017.09.017.

[6] T. Heberer, J. Hydrol. 266 175-189 (2002). doi :10.1016/S00221694(02)00165-8.

[7] M.M. Ahmed, S. Chiron, Water Res. 48 229-236 (2014). doi: 10.1016/j.watres.2013.09.033.

[8] B.Gy. Plósz, K.H. Langford, K.V. Thomas, Biotechnol. Bioeng. 109 2757-2769 (2012). doi:10.1002/bit.24553.

[9] P. Verlicchi, M. Al Aukidy, E. Zambello, Sci. Total Environ. 429 123-155

(2012) doi: 10.1016/j.scitotenv.2012.04.028.

[10] A.B. Rostam, M. Taghizadeh, J. Environ. Chem. Eng. 8104566 (2020). doi:10.1016/j.jece.2020.104566.

[11] B. Dalecka, M. Strods, P. Cacivkins, E. Ziverte, G.K. Rajarao, T. Juhna, Environ. Adv. 5 100086 (2021). doi:10.1016/j.envadv.2021.100086.

[12] W.O. Khunjar, S.A. Mackintosh, J. Skotnicka-Pitak, S. Baik, D.S. Aga, N.G. Love, Sci. Technol. 45 3605-3612 (2011). doi: 10.1021/es1037035.

[13] F. Younas, N.K. Niazi, I. Bibi, M. Afzal, K. Hussain, M. Shahid, Z. Aslam, S. Bashir, M.M. Hussain, J. Bundschuh, J. Hazard. Mater. 422126926 (2022). doi:10.1016/j.jhazmat.2021.126926.

[14] S. Lu, L. Liu, Q. Yang, H. Demissie, R. Jiao, G. An, D. Wang, Sci. Total Environ. 786 147508 (2021). doi: 10.1016/j.scitotenv.2021.147508. 
[15] M.N. Ardakani, G. Badalians Gholikandi, Biomass Bioenergy. 141105726 (2020). doi: 10.1016/j.biombioe.2020.105726.

[16] M. Yegane Badi, M. Vosoughi, H. Sadeghi, S.A. Mokhtari, J. Mehralipour, Int. J. Environ. Anal. Chem. 1-14 (2020). doi: 10.1080/03067319.2020.1726335.

[17] M. Yeganeh, E. Charkhloo, H.R. Sobhi, A. Esrafili, M. Gholami, , Chem. Eng. J. 428130081 (2022). doi:10.1016/j.cej.2021.130081.

[18] M. Yeganeh, S. Fallah Jokandan, M. Rahmatinia, B. Kakavandi, M.

Noorisepehr, E. Dehghanifard, M.M. Baneshi, , Int. J. Environ. Anal. Chem. 1-18 (2020). doi: 10.1080/03067319.2020.1839440.

[19] A. Azari, M. Yeganeh, M. Gholami, M. Salari, J. Hazard. Mater. 418126348 (2021). doi: 10.1016/j.jhazmat.2021.126348.

[20] A.M. Deegan, B. Shaik, K. Nolan, K. Urell, M. Oelgemöller, J. Tobin, A.

Morrissey, Int. J. Environ. Sci. Technol. 8 649-666 (2011). doi: 10.1007/BF03326250.

[21] Y. Hong, H. Zhou, Z. Xiong, Y. Liu, G. Yao, B. Lai, , Chem. Eng. J. 391 123604 (2020). doi:10.1016/j.cej.2019.123604.

[22] D.P. Mohapatra, S.K. Brar, R. Daghrir, R.D. Tyagi, P. Picard, R.Y. Surampalli, P. Drogui, Sci. Total Environ. 485-486 263-269 (2014). doi: 10.1016/j.scitotenv.2014.03.089.

[23] M. Nawaz, W. Miran, J. Jang, D.S. Lee, Appl. Catal. B Environ. 203 85-95 (2017). doi:10.1016/j.apcatb.2016.10.007.

[24] M. Gar Alalm, A. Tawfik, S. Ookawara, J. Environ. Chem. Eng. 4 1929-1937 (2016). doi: 10.1016/j.jece.2016.03.023.

[25] Q. Li, F. Li, Chem. Eng. J. 421129915 (2021). doi: 10.1016/j.cej.2021.129915.

[26] Y. Gu, J. Yperman, R. Carleer, J. D'Haen, J. Maggen, S. Vanderheyden, K.

Vanreppelen, R.M. Garcia, , Chemosphere. 217 724-731 (2019).

doi: 10.1016/j.chemosphere.2018.11.068.

[27] A.Ö.A. Tuna, E. Özdemir, E.B. Simsek, U. Beker, Water. Air. Soil Pollut. 224 1685 (2013). doi: 0.1007/s11270-013-1685-z.

[28] M.A. Watson, A. Tubić, J. Agbaba, J. Nikić, S. Maletić, J. Molnar Jazić, B.

Dalmacija, J. Hazard. Mater. 312 150-158 (2016). doi: 0.1016/j.jhazmat.2016.03.002.

[29] K. Rajkumar, M. Muthukumar, Appl. Water Sci. 7 637-652 (2017). doi: 10.1007/s13201-015-0276-0.

[30] A. Carabin, P. Drogui, D. Robert, Water. Air. Soil Pollut. 227122 (2016) . doi 10.1007/s11270-016-2819-x.

[31] D. Lambropoulou, E. Evgenidou, V. Saliverou, C. Kosma, I. Konstantinou, J. Hazard. Mater. 323 513-526 (2017). doi: 10.1016/j.jhazmat.2016.04.074.

[32] K. Patidar, M. Vashishtha, Water. Air. Soil Pollut. 231526 (2020). doi: 10.1007/s11270-020-04893-4.

[33] E.M. El Mouchtari, C. Daou, S. Rafqah, F. Najjar, H. Anane, A. Piram, A. Hamade, S. Briche, P. Wong-Wah-Chung, J. Photochem. Photobiol. Chem. 388112183 (2020). doi: 10.1016/j.jphotochem.2019.112183.

[34] Z. Schmidtová, R. Kodešová, K. Grabicová, M. Kočárek, M. Fér, H. Švecová, A. Klement, A. Nikodem, R. Grabic, J. Contam. Hydrol. 234103680 (2020). doi: 10.1016/j.jconhyd.2020.103680.

[35] R. Meribout, Y. Zuo, A.A. Khodja, A. Piram, S. Lebarillier, J. Cheng, C. Wang, P. Wong-Wah-Chung, J. Photochem. Photobiol. Chem. 328 105-113 (2016). doi: 10.1016/j.jphotochem.2016.04.024. 
[36] G.E.P. Box, K.B. Wilson, J. R. Stat. Soc. Ser. B Methodol. 13 1-38 (1951). doi:10.1111/j.2517-6161.1951.tb00067.x.

[37] S. Rafqah, P.W.-W. Chung, C. Forano, M. Sarakha, J. Photochem. Photobiol. Chem. 199 297-302 (2008). doi: 0.1016/j.jphotochem.2008.06.012.

[38] R. Tauler, B. Walczak, S.D. Brown, Elsevier Science, London, 2011. http://qut.eblib.com.au/patron/FullRecord.aspx?p=631910 (accessed May 3, 2021). [39] R.H. Myers, D.C. Montgomery, C.M. Anderson-Cook, Fourth edition, Wiley, Hoboken, (New Jersey, 2016).

[40] J. Singla, V.K. Sangal, A. Singh, A. Verma, J. Environ. Manage. 255109847. doi:10.1016/j.jenvman.2019.109847.

[41] F.S. Moosavi, T. Tavakoli, Environ. Sci. Pollut. Res. 23 23262-23270 (2016). doi: 10.1007/s11356-016-7349-y.

[42] Y. Deng, Y.S. Ok, D. Mohan, C.U. Pittman, X. Dou, Environ. Res. 169 434-444 (2019). doi: 10.1016/j.envres.2018.11.035.

[43] N.B. Parilti, C.S.U. Demirel, M. Bekbolet, J. Photochem. Photobiol. Chem. 225 26-35 (2011). doi: 10.1016/j.jphotochem.2011.09.021.

[44] M. Zulfiqar, M.F.R. Samsudin, S. Sufian, J. Photochem. Photobiol. Chem. 384 112039 (2019). doi: 10.1016/j.jphotochem.2019.112039.

[45] K. Govindan, H.T. Chandran, M. Raja, S.U. Maheswari, M. Rangarajan, J.

Photochem. Photobiol. Chem. 341 146-156 (2017).

doi: 10.1016/j.jphotochem.2017.03.025.

[46] N. Tzikalos, V. Belessi, D. Lambropoulou, Environ. Sci. Pollut. Res. 20 (2013) 2305-2320. doi:10.1007/s11356-012-1106-7.

[47] M.A. Bezerra, R.E. Santelli, E.P. Oliveira, L.S. Villar, L.A. Escaleira, Talanta. 76 965-977 (2008). doi: 10.1016/j.talanta.2008.05.019.

[48] M. Abdulgader, Q.J. Yu, A.A. Zinatizadeh, P. Williams, Z. Rahimi, J. Environ. Chem. Eng. 8103797 (2020). doi: 10.1016/j.jece.2020.103797.

[49] A. Majumdar, A. Pal, J. Environ. Chem. Eng. 8103645 (2020). doi: 10.1016/j.jece.2019.103645.

[50] M. Zulfiqar, S. Chowdhury, A.A. Omar, A.A. Siyal, S. Sufian, Environ. Sci. Pollut. Res. (2020). doi: 10.1007/s11356-020-09674-4.

[51] C.H. Giles, T.H. MacEwan, S.N. Nakhwa, D. Smith, J. Chem. Soc. Resumed. 7863973 (1960). doi: 10.1039/jr9600003973.

[52] S. Rafqah, P. Wong-Wah-Chung, A. Aamili, M. Sarakha, , J. Mol. Catal. Chem. 237 (2005) 50-59. https://doi.org/10.1016/j.molcata.2005.03.044.

[53] Q. Li, F. Li, Recent advances in molecular oxygen activation via photocatalysis and its application in oxidation reactions, Chem. Eng. J. 421129915 (2021).

doi:10.1016/j.cej.2021.129915.

[54] J. Prakash, S. Sun, H.C. Swart, R.K. Gupta, N, Appl. Mater. Today. 11135 (2018) . doi: 10.1016/j.apmt.2018.02.002.

[55] D.N. Nguyen, H.M. Bui, H.Q. Nguyen, Biotechnol. Bioeng., Elsevier,: pp. 161183 (2020). doi: 0.1016/B978-0-12-819594-9.00007-3.

[56] E.M. El Mouchtari, L. Bahsis, L. El Mersly, H. Anane, S. Lebarillier, A. Piram, S. Briche, P. Wong-Wah-Chung, S. Rafqah, , Int. J. Environ. Res. 15 135-147 (2021). doi:10.1007/s41742-020-00300-2.

[57] E.H. Mourid, E.M. El Mouchtari, L. El Mersly, L. Benaziz, S. Rafqah, M.

Lakraimi, J. Photochem. Photobiol. Chem. 396112530 (2020).

doi:10.1016/j.jphotochem.2020.112530. 
[58] L. EL Mersly, E.M. El Mouchtari, E.M. Moujahid, C. Forano, M. El Haddad, S. Briche, A. Alaoui Tahiri, S. Rafqah, J. Sci. Adv. Mater. Devices. 6 118-126 (2021). doi:10.1016/j.jsamd.2020.08.002.

[59] M. Turk Sekulic, N. Boskovic, M. Milanovic, N. Grujic Letic, E. Gligoric, S. Pap,, J. Mol. Liq. 284 372-382 (2019). doi:10.1016/j.molliq.2019.04.020.

[60] Z. Yu, S. Peldszus, P.M. Huck, Water Res. 42 2873-2882 (2008). doi: 10.1016/j.watres.2008.02.020.

[61] international-conference-harmonisation-technical-requirements-registrationpharmaceuticals-human-use_en-19.pdf, (2009). https://www.fda.gov/regulatoryinformation/search-fda-guidance-documents/q8r2-pharmaceutical-development. [62] K. Ng, N. Rajagopalan, A, in: A.S. Rathore, R. Mhatre (Eds.), Qual. Des. Biopharm., John Wiley \& Sons, Inc., Hoboken, NJ, USA,:pp. 161-174 (2009) . doi: 0.1002/9780470466315.ch9.

[63] D. Manzon, M. Claeys-Bruno, S. Declomesnil, C. Carité, M. Sergent, , Chemom. Intell. Lab. Syst. 200104002 (2020). doi: 10.1016/j.chemolab.2020.104002.

[64] G. Derringer, R. Suich, J. Qual. Technol. 12 214-219 (1980). doi: 10.1080/00224065.1980.11980968.

[65] R.A. French, A. R. Jacobson, B. Kim, S. L. Isley, R. L. Penn, P. C. Baveye Environ. Sci. Technol. 2009, 43, 5, 1354-1359 https://doi.org/10.1021/es802628n 